\title{
A FAMÍLIA E OS PAPEIS DE GÊNERO NA ADOLESCÊNCIA
}

\author{
ROLES FAMILIARES Y DE GÉNERO EN LA ADOLESCENCIA \\ FAMILY AND GENDER ROLES ON ADOLESCENCE
}

\author{
Julia Baerlocher Carvalhơ ${ }^{1}$ Mônica Cristina Melo ${ }^{1}$ \\ ${ }^{\mathbf{1}}$ Faculdade Pernambucana de Saúde, Recife/PE, Brasil
}

RESUMO: Os papeis femininos e masculinos na sociedade brasileira passaram a ser questionados e modificados, afetando a família e revelando problemáticas que demandam atenção, apesar da suposta igualdade entre os sexos alcançados na sociedade contemporânea. O estudo é de abordagem qualitativa, utilizou-se entrevistas e a análise temática de conteúdo. Participaram adolescentes entre 14 e 16 anos. Foi possível observar que as interações e socialização ocorrida dentro do âmbito familiar ainda funciona como mecanismo de imposição e reforço de papeis "naturalizados" como femininos e masculinos, contribuindo para a persistência das condições sociais de desigualdade. Diante desse contexto, recomendase práticas de educação continuada nas escolas, sociedades e através de políticas públicas voltadas para facilitar o processo de ressignificação dos papeis de gênero na atualidade.

PALAVRAS-CHAVE: Violência psicológica; Gênero; Família.

RESUMEN: Los roles femeninos y masculinos en la sociedad brasileña han sido cuestionados y modificados, afectando a la familia y revelando problemas que requieren atención, a pesar de la supuesta igualdad de género lograda en la sociedad contemporánea. El estudio tiene un enfoque cualitativo, se utilizaron entrevistas y análisis temática de contenido. Participaron adolescentes entre 14 y 16 años. Se observó que las interacciones y la socialización que ocurrieron dentro de la familia todavía funcionan como un mecanismo de imposición y refuerzo de roles "naturalizados" como mujeres y hombres que contribuyen a la persistencia de las condiciones sociales de desigualdad. En este contexto, se recomiendan prácticas de educación continua en las escuelas, las sociedades y a través de políticas públicas destinadas a facilitar el proceso de resignificación de los roles de género en la actualidad

PALABRAS CLAVE: Violência psicológica; Género; Familia.

ABSTRACT: Female and male roles in Brazilian society have been questioned and modified, affecting the family and revealing issues that require attention despite the supposed gender equality achieved in contemporary society. The study has a qualitative approach, and interviews and thematic content analysis were used. Participants were adolescents between 14 and 16 years old. It was observed that the interactions and socialization that occur within the family still work as mechanisms of imposition and reinforcement of female and male "naturalized" roles, which contributes to the persistence of social conditions of inequality. In this context, continuing education practices are recommended in schools, societies and through public policies aimed at facilitating the process of resignification of gender roles today.

KEYWORDS: Psychological violence; Gender; Family. 


\section{Introdução}

A partir da década de 60 a sociedade brasileira passa a sofrer um intenso processo de transformação social influenciado por movimentos feministas que revolucionaram as relações sociais e de poder desde os primórdios do século XX e desencadearam uma série de novos contextos e configurações na interação entre os sexos. Os papéis femininos e masculinos dentro da sociedade brasileira passam a ser problematizados e modificados, afetando a instituição social primária de excelência: a família (Goldenberg, 2001). Com a emergência de novos tipos de configurações familiares, que se afastam do ideal patriarcal de família até então predominante no país, há uma renovação dos valores que implicam em uma mudança social marcante(Goldani, 1993).

Contudo, a violência e a desigualdade de gênero ainda permeiam a estrutura da sociedade e da família contemporânea, na qual a imposição de expectativas de papéis de gênero são cenas comuns do seu cotidiano (Praun, 2011). Acontece que mesmo com a implementação e criação de modelos de igualdade jurídica entre os sexos e com uma ampliação na gama de oportunidades e opções de vida para mulheres devido à constitucionalização de seus direitos básicos, as desigualdades de gênero se mantém através de condições sociais e políticas arraigadas na sociedade que buscam defender as desigualdades como resultantes de diferenças naturais entre homens e mulheres (Cursino, 2010). Para Elias e Gauer (2014), a violência de gênero estaria impregnada na cultura social, e, portanto, para que seja possível superá-la e alcançar uma maior igualdade de gênero são necessárias práticas educativas capazes de modificar ideologias que se encontram cristalizadas na cultura.

Segundo Scott (1990), diferentes culturas utilizam a distinção biológica do sexo para potencializar supostas características femininas e masculinas como naturais quando, na verdade, as mesmas são apenas resultantes de processos de educação e socialização. Desse modo, o conceito de gênero é aqui entendido como um produto social, cultural e histórico, utilizado como ferramenta para desnaturalização de papéis e identidades de gênero em contraposição ao conceito de sexo que se restringe a dimensão biológica. Assim, a associação entre gênero e família se faz pela perpetuação de princípios tradicionais constituintes da socialização e educação dos filhos, pelo viés da violência psicológica, como comentam Koller e Narvaz (2004): "A opressão (de gênero) pode ocorrer como relação de poder que se reproduz através da família, socializando seus membros conforme os ditames da cultura vigente, internalizando, reproduzindo, ocultando a opressão vivida” (p. 8).

No âmbito privado da família, muitas vezes posturas de dominação, autoridade, controle, força e violência são naturalizados e vistos como constituintes desse contexto "particular" (Bidarra \& Gregoria, 2008). Portanto, é possível considerar a família como um contexto privilegiado de reprodução ideológica e de aprendizado social. Tradicionalmente, há uma cultura que exige que a educação de meninos e meninas seja diferente. Porém, desde a descoberta do sexo, os pais passam a programar e planejar a vida do bebê, como o espaço físico, as características físicas, os brinquedos de acordo com o seu gênero, e com o seu crescimento passará a atribuir papéis e expectativas sobre seu filho também de acordo com o mesmo (Nascimento \& Trindade, 2010).

Segundo Duveen (1994) durante o desenvolvimento da identidade de gênero "A força da categorização nas representações de gênero que circulam em volta da criança é tão forte que ela sempre vai aparecer como uma menina ou como um menino, desenvolvendo identidades sociais específicas" (p. 266). A questão central dessa temática é investigar se há, de fato, diferenças radicais na educação de meninos e meninas mesmo com o cenário atual que 
pressupõe uma igualdade plena entre homens e mulheres; sendo esse radicalismo supostamente sedimentado através da violência psicológica.

A violência psicológica é considerada o tipo de violência mais corriqueira, e, na maioria das vezes, aparece interligada a outros tipos de violência, contudo, por sua difícil identificação e por sua suposta naturalização no que diz respeito a interações sociais, principalmente do âmbito privado, a violência psicológica tende a ser menosprezada. Ofensas constantes, constrangimento, privação de recursos, humilhações, manipulações, isolamento, chantagem, rejeição, são alguns exemplos de violência psicológica, que pode ser entendida como qualquer ação ou omissão que cause prejuízo a saúde e ao desenvolvimento psicológico do sujeito (Russo, Trindade, Dantas, \& Nogueira, 2014).

A violência psicológica vivida dentro do âmbito familiar produz efeitos graves nos indivíduos e dificilmente é denunciada, uma vez que a violência se torna naturalizada quando é culturalmente entendida como constitutiva de uma relação, como no caso da violência intrafamiliar. Nessa relação, a violência (doméstica) costuma estar silenciada, dada a pouca visibilidade do espaço em que ocorre, o espaço privado da família e sob a influência da autoridade patriarcal (Bidarra \& Gregoria, 2008).

Com isso, a escolha de dar voz aos adolescentes, na busca de resquícios de violência psicológica com ênfase em papéis de gênero na educação familiar não é arbitrária. A adolescência é um período marcado por contestações, crises, e pela emergência da sexualidade, portanto, novos temas passam a ser debatidos e questionados dentro do ambiente familiar por esses adolescentes que estão vivenciando um período de intensas mudanças psicossociais (Mayorga, 2006). A depreciação, ridicularização, constrangimento ou qualquer outro tipo de violência psicológica atua como bloqueio de autoaceitação do adolescente, o que acarreta em problemas de autoestima, afeta a construção de uma identidade saudável e pode funcionar como mecanismo de reforço de desigualdades de gênero, uma vez que é capaz de distorcer a visão do que é correto, do que é natural e do que é aceitável numa perspectiva de papéis masculinos e femininos (Pratta \& Santos, 2007).

\section{Método}

O estudo teve como objetivo compreender a percepção dos adolescentes sobre a imposição dos papéis de gênero através de sua educação familiar. Trata-se de uma pesquisa qualitativa realizada em uma escola particular localizada na região metropolitana de Recife, Pernambuco, entre setembro de 2015 e julho de 2016. Para coleta dos dados utilizou-se um questionário sociodemográfico com perguntas sobre o número de membros da família, estado civil dos pais, escolaridade e renda e uma entrevista, que foi gravada e analisada de acordo com a análise temática de conteúdo (Bardin, 1979).

As entrevistas foram transcritas integralmente para serem analisadas dentro de uma perspectiva de investigação social de acordo com Bardin (1979), de modo que buscou-se compreender estruturas e padrões através do discurso do entrevistado. A análise temática foi utilizada seguindo seus passos tradicionais de pré-análise, exploração do material, tratamento dos resultados obtidos e interpretação. A pesquisa foi aprovada pelo Comitê de Ética em Pesquisa do Instituto de Medicina Integral Professor Fernando Figueira, parecer número $1.334,669$, e tratou-se de uma pesquisa do Projeto de Iniciação Científica (PIBIC) do Conselho Nacional de Desenvolvimento Científico e Tecnológico (CNPq). 


\section{Resultados e discussão}

\section{Características sociodemograficas dos participantes}

Participaram do estudo nove estudantes do primeiro e segundo ano do ensino médio, sendo oito meninas e um menino com idades entre 14 e 16 anos. O tamanho das famílias variou entre 4 a 8 pessoas, a maioria dos pais eram casados e o pai era o principal responsável pelo sustento da família. O nível de escolaridade dos pais variou entre ensino médio incompleto até doutorado, já a renda mensal das famílias variou entre $\mathrm{R} \$ 1.734,00$ e acima de $\mathrm{R} \$ 9.745,00$. Informação colhida sem confirmação documental. De maneira geral, é possível supor que se tratava de famílias entre classe média baixa e alta. Além disso, a maior parte dos entrevistados morava em casa e usufruía do serviço de empregada doméstica durante a semana.

Conhecer sobre a condição econômica dos participantes é um fator importante. A discussão sobre desigualdade de gênero está atrelada a outros tipos de desigualdades como a social e a racial. Sabe-se que é uma tarefa difícil realizar uma pesquisa sobre gênero sem situar o cenário social dos seus participantes, uma vez que o presente estudo foi desenvolvido em um país socialmente estratificado onde as relações sociais mudam de acordo com a classe social, sendo as mesmas influentes nas escolhas, oportunidades de vida e convívio dos seus membros. Nesse aspecto, de acordo com Weber (1971), "situação de classe" consiste na disposição de bens e habilidades, devido à renda e às chances de vida e tipo de poder, ou falta dele, presentes em decorrência do pertencimento a determinada ordem econômica.

Desse modo, pode-se pensar que a relação entre desigualdade de gênero e social é praticamente simbiótica, visto que a assimetria na divisão do trabalho e da renda de acordo com o gênero está presente em todas as partes do mundo (Santos, 2008). No que diz respeito especificamente à classe média, foi observado em pesquisas anteriores (Cursino, 2010; Cortez \& De Souza, 2013) que a divisão de tarefas domésticas pautadas no gênero chega a níveis elevados em empregos de classe média, embora exista uma tendência a considerar que casais de classe média seriam mais igualitários, contribuindo justamente para a transformação social da família, aderindo a novos padrões de comportamento e divisão de tarefas de maneira simétrica, a realidade ainda revela alguns comportamentos que contradizem esse pensamento. É fato que algumas mudanças estão acontecendo, porém, no cenário geral, ainda há a permanência de valores sexistas que promovem uma hierarquia entre os sexos no contexto do desempenho de papéis sociais e expectativas relacionadas a eles no âmbito familiar, por isso é possível pensar que, em relação à desigualdade de gênero, a classe média não se encontra tão distante da classe baixa (Carvalho \& Machado, 2006).

Quando se observa o resultado de estudos sobre gênero, adolescência e família, revisões bibliográficas sobre violência de gênero e intrageracionalidade (Gomes et al., 2007) e papel da família no desenvolvimento psicológico de adolescentes (Pratta \& Santos, 2007), a família é sinalizada como centro do desenvolvimento humano e como local de reprodução da violência de gênero, construída a partir das relações desiguais entre os sexos naturalizadas no processo de socialização.

\section{Analise qualitativa}

Através da sistematização e classificação dos componentes dos discursos dos entrevistados foi possível elaborar um quadro temático com os aspectos presentes e relevantes do material coletado que, a priori, remeteu à seguinte reflexão: no aspecto qualitativo, 
identificou-se pesquisas que sinalizam associação entre o papel da sexualidade e da educação sexual na adolescência com a divisão de trabalhos domésticos de acordo com o gênero. Essa associação também foi encontrada no presente estudo. Sendo assim, constata-se que a educação e discussão de temas como gênero e sexualidade são fundamentais para o incentivo de uma vivência sexual sem temores, culpas e preconceitos (Fonseca \& Gomes, 2004). Outro achado interessante foi o que diz respeito ao trabalho doméstico, que foi apontado até mesmo no discurso de jovens meninas como algo feminino, pertencente à natureza da mulher (Santana \& Dimenstein, 2005). Nessa pesquisa, embora os adolescentes tenham questionado muito essa exclusividade feminina nos afazeres domésticos, a realidade vivenciada em casa condizia com uma divisão assimétrica pautada no gênero.

Como resultado da análise qualitativa do material foram identificadas quatro categorias temáticas, sendo elas: o desconhecimento sobre gênero e violência psicológica; a confusão acerca dos conceitos de gênero e sexualidade; a divisão sexista das tarefas domésticas e a identificação de comportamentos sexistas no cotidiano familiar.

\section{Desconhecimento sobre gênero e violência psicológica}

Sobre esse tema, o conteúdo das falas dos participantes foi praticamente homogêneo: para sete entrevistados gênero consiste em masculino e feminino, cenário que coincide com a perspectiva de Praun (2011). O autor defende que, para muitos, a ideia de gênero é baseada no senso comum. Mesmo considerando a gravidade do desconhecimento por parte de adolescentes de um conceito entendido como princípio organizador da estrutura de relações de poder entre os sexos, e como uma espécie de "performance" pela qual homens e mulheres se posicionam em relação uns aos outros e constroem sua própria subjetividade, é possível entender que tais conceitos parecem que ainda não estão popularizados (Cursino, 2010).

É importante ressaltar as ideias de Mead (1982) nesse aspecto, já que o mesmo destaca a identidade como um reflexo da estrutura social quando poderia funcionar como força de conservação ou transformação da mesma. Assim, para que uma efetiva transformação seja possível, é necessária uma consciência crítica sobre as relações de poder que atuam nas construções da realidade dos grupos (Neves \& Nogueira, 2003).

Sabe-se que o desconhecimento do conceito não deixa esses adolescentes totalmente vulneráveis à opressão de gênero, porém, a importância de um conhecimento básico de estudos de gênero para fins reflexivos sobre a sua posição e o seu papel dentro da sociedade é inegável e funciona como estratégia de prevenção de preconceitos, de disseminação de ignorância e como ferramenta de transformação social.

Ao longo das entrevistas, mesmo com o suposto desconhecimento sobre gênero e feminismo, ficou claro que isso não afetava a capacidade dos adolescentes de identificar situações de sexismo e de se posicionar contra elas. No entanto, algo que chamou a atenção no conteúdo das falas foi que, mesmo com pouca informação sobre questões de diferenciação entre sexo e gênero, houve por parte dos participantes a necessidade de desculpabilizar os pais por comportamentos que reforçam estigmas que podem promover desigualdade na sociedade. Estes eram justificados por "serem de outra época” ou "do interior" e não estarem muito acostumados a conviver com determinadas posturas. Em algumas falas foi possível perceber que os adolescentes adotavam uma postura defensiva, como é possível observar na fala de Gisele (15): "Eu até entendo ele ter esse preconceito porque ele nasceu numa geração que tinha esse preconceito" 
Uma vez que a socialização na cultura patriarcal sexista vigente implica numa aceitação, por parte das mulheres, de situações que envolvem desigualdade e violação, isso poderia explicar essa necessidade de desculpabilização dos pais recorrente nos discursos, como também, o desconhecimento sobre algumas questões veiculadas sobre gênero na atualidade (Koller \& Narvaz, 2004).

Dentre as respostas que sinalizaram diferença entre as limitações inerentes ao masculino-feminino, a participante Hélida (16) admitiu que costumava pensar que se referia a meninos e meninas, no entanto, sabia que hoje em dia englobava novos conceitos que ela não tinha conhecimento. Um entrevistado demonstrou compreensão sobre o conceito de gênero. Para Daniel (15), gênero é "como a pessoa se identifica, a forma como ela age... Seria a identidade da pessoa”. Por outro lado, no decorrer da entrevista, Daniel se mostrou confuso em relação aos conceitos de gênero e sexualidade.

Diante dessas falas, é relevante salientar que ambas, tanto a identidade de gênero como a sexual são conceitos que estão sendo construídos socialmente e a apropriação desses conceitos ainda está em curso pela sociedade. Quanto à diferença entre papel e identidade de gênero, Stoller (1993) elucida essa distinção: enquanto ao papel de gênero consiste nos padrões de comportamentos adequados aos dois sexos no convívio social, a identidade de gênero diz respeito à "mescla de masculinidade e feminilidade" que todos os seres humanos apresentam em graus diferentes.

Quanto aos discursos dos adolescentes sobre violência psicológica, alguns demonstraram compreensão sobre o tema. Este fato pode ser justificado porque a violência psicológica abrange uma série de comportamentos e alguns deles foram citados nos discursos dos adolescentes. Manuela (16), na sua fala, indagou se seria uma espécie de chantagem, já Marina (15) nos perguntou se era um tipo de bullying. De maneira geral, todos pareceram concordar que se tratava de um tipo de interferência psicológica que afetava o pensamento de modo violento.

Apenas dois entrevistados afirmaram não saber do que se tratava. E poucos souberam exemplificar situações do seu cotidiano que poderiam ser descritas como violência psicológica, até mesmo os que afirmaram acreditar que já havia ocorrido em casa. No entanto, no discurso de duas participantes, a questão foi relacionada com alguma vivência familiar. Marina (15) contou um pouco sobre como o fato de os afazeres domésticos se restringirem a ela e a sua mãe podem gerar uma influência negativa nela e Gisele (15) contou sobre o problema que é gerado em casa quando seu padrasto vê o seu filho mais novo assistindo a um reality show de drag queens: "Ele briga muito com a gente, sabe, fala que isso é errado, ... que isso é uma coisa muito bizarra".

Para Silva, Coelho e Caponi (2007) a não identificação da violência psicológica por parte das vítimas é bastante comum, visto que muitas vezes estão associadas a fatores emocionais dificultando o seu reconhecimento. De fato, no presente estudo, excluindo os estudantes que afirmaram não saber do que se tratava a violência psicológica, apenas um afirmou que ela não ocorria em sua casa, enquanto os outros disseram apenas pensar que não ou então não conseguiam descrever casos quando respondiam positivamente.

A violência psicológica intrafamiliar é muitas vezes justificada como forma de educação e de correção de comportamentos indisciplinados o que também explicaria o porquê dela se apresentar de maneira tão confusa para esses adolescentes (Abranches \& Assis, 2011 ). O limite entre educação rígida e práticas educativas violentas parece não estar claro para eles. Com isso, é essencial reforçar a necessidade de práticas educativas voltadas para 
a conscientização sobre o tema, visto que a violência psicológica alcançou terceiro lugar de atendimento no âmbito do Sistema Único de Saúde de acordo com o Mapa da Violência realizado em 2012 e costuma ser uma violação altamente tolerada e impune dentro da sociedade, mas que apresenta efeitos tão ou mais graves que a própria violência física (RUSSO et al., 2014).

\section{Confusão acerca dos conceitos de gênero e sexualidade}

A emergência da sexualidade e a intensa curiosidade sobre o tema é uma característica forte da adolescência. Somado isso ao desconhecimento sobre a temática de gênero, questões ligadas à orientação sexual surgiram tanto quanto as de gênero durante as entrevistas. O início da puberdade e a entrada na esfera da sexualidade são citados por Gisele (15) como motivos para o seu padrasto estar tão temeroso que seu filho seja influenciado por ideias homossexuais: "Digamos que meu padrasto tem medo dele ser, dele virar... gay, nê"

Historicamente, o termo "orientação sexual" nasce em 1980 substituindo o que era denominado até então de "preferência sexual", a sua definição é alvo de debate entre muitas correntes e articulações teóricas dentro da psicologia, contudo, no âmbito da psicologia social a perspectiva mais consensual é que se trata do direcionamento dos impulsos sexuais de um sujeito, do seu desejo e de suas escolhas afetivas (De Sousa, 2011). Sabe-se que a orientação sexual pode ser entendida como um fenômeno tanto particular quanto coletivo e político, de fato, cada sociedade procura impor uma série de normas sobre ela, nas quais estão em jogo relações de poder.

A orientação sexual é resultante das diversas relações estabelecidas pelo indivíduo ao longo da vida, a maneira como o mesmo interage com seu mundo psíquico, com padrões culturais de gênero e a trajetória pessoal com ênfase nos relacionamentos familiares e sociais funcionam como alicerces para a construção da sexualidade de cada um (De Sousa, 2011). Portanto, o papel da família e do gênero são essenciais para a construção da identidade sexual de um sujeito e, assim, o medo e a repressão do padrasto de Gisele (15) podem refletir na saúde psíquica de seu irmão ou transformá-lo em mais um multiplicador de estigmas.

Vale ressaltar os sinais de confusão entre os conceitos apresentados pelos adolescentes, que acreditavam que gênero e sexualidade consistiam na mesma coisa. Ao ser questionada se já havia conversado sobre gênero com seus pais, Manuela (16) começou respondendo: "Já, mas não pra discutir o meu, entendeu? Sempre muito de boa [sic], sempre mulher" e em seguida continuou a falar sobre homossexualidade. Já Daniel (15) quando indagado sobre o que seria "coisa de menino e coisa de menina", afirmou:

Eu divido em menino heterossexual e homossexual... pra mim, menino heterossexual é bola, carrinho, e menino homossexual não é tão essas coisas de jogar bola, brincar com o carrinho, é mais na dele, talvez até boneca. E menina seria boneca.

Desse modo, é interessante constatar que esses pensamentos demonstram como a socialização de características masculinas e femininas como naturais ainda são altamente efetivas e constituintes da educação familiar. Money (1998) explica como a auto percepção do que é ser menino e menina é dada por aspectos culturais como cor de roupa e tipo de brinquedo. Assim, o que a fala de Manuela e Daniel evidenciam é justamente uma suposta dependência entre gênero e sexualidade disseminado no senso comum, porém contestado e negado 
cientificamente, Manuela (16) acredita que por "sempre haver sido mulher" a sua sexualidade está clara, e Daniel pensa que as preferências por determinado tipo de brinquedo condiz com o direcionamento sexual do indivíduo e não com a maneira pela qual ele se identifica, contradizendo sua própria fala sobre gênero citada anteriormente, demonstrando que, provavelmente, ele estava se referindo a sexualidade. Gisele (15) também segue a mesma linha de pensamento dos colegas, contudo, aparentemente, com um olhar mais crítico:

Quando eu era pequena eu brincava de cartinha de yugioh [sic] com meus primos e sou hétero [sic], isso não mudou nada na minha formação, entendeu? ... Minhas primas elas se jogavam na árvore assim, coisa que "menino faz" e são meninas que gostam de meninos, entendeu? Isso de você tem que botar só menina pra brincar de boneca pra ela ser menina e gostar de menino quando ela crescer... Não.

Pode-se observar através da fala que, ao mesmo tempo em que ela contesta padrões de gênero, ao não concordar com comportamentos específicos de menino e de menina na infância, ela os relaciona com sexualidade. Importante salientar que, de maneira geral, tem-se a impressão de que esses adolescentes apresentam uma visão desses temas como algo voltado ao exterior das pessoas e unicamente relacionado à atração sexual e não que meninos e meninas devem ser educados da mesma maneira e com o mesmo tipo de brincadeiras e jogos. Parece que não está claro para eles que um menino pode gostar de bonecas e meninas de esportes envolvendo lutas, o que parece é que tais fatores estão sendo automaticamente relacionados à orientação sexual. Nessa perspectiva, é fácil identificar resquícios da sociedade heteronormativa discutida por Foucault (1988).

Entretanto, destaca-se que as opiniões dos adolescentes sobre sexualidade parecem promissoras pois, embora muitos tenham afirmado pertencer à famílias religiosas ou a famílias que tinham problemas com a homoafetividade, sendo comum o discurso do "eu respeito, mas não aceito" ou "tenho amigos gays mas não acho que isso seja o certo" por parte dos pais, esses adolescentes se posicionaram de maneira mais aberta e como legítimos contestadores dos pais nesse quesito.

\section{Divisão sexista das tarefas domésticas}

No caso dessa pesquisa, os resultados revelaram que somente duas das entrevistadas afirmaram que o trabalho doméstico é dividido de forma igualitária em sua casa. Até mesmo em um dos casos, Camila (16) responde que há a divisão em sua família, no entanto ela comenta: "A gente divide... só que meu pai nunca faz, ele passa o dia todo dormindo, aí eu fico brigando com ele, mas...” Além disso, é notável que até mesmo nos casos de irmãos, como já havia sido constatado por Carvalho e Machado (2006), as filhas ficam mais responsáveis pelos serviços domésticos:

Minha mãe, ela é mais... ela vai pra cozinha mais vezes, mas meu pai e eu ajudo [sic]
de vez em quando, mas, ultimamente é mais minha mãe que faz essas coisas, meu pai vai
fazer outras tarefa... A minha irmã também faz mais tarefas como a minha mãe, com ela,
como lavar louça. (Daniel, 15)

A divisão de tarefas domésticas entre os casais na sociedade atual vem sido tema de muitas pesquisas na área de gênero justamente por ser um setor da vida familiar que demonstra a resistência de valores patriarcais e sexistas no cotidiano e como a reprodução de 
papeis de gênero tradicionais ainda é bastante comum. De fato, pesquisas têm demonstrado como a mulher ainda é considerada única responsável pelo trabalho doméstico e como características femininas são usadas como naturalmente domésticas e acabam aprisionando grande parte das mulheres em uma jornada altamente exaustiva de trabalho (Cursino, 2010; Carvalho \& Machado, 2006; Cortez \& De Souza, 2013; Jablonski, 2010).

É interessante enfatizar o pensamento bastante aceito de que homens "ajudam" no serviço doméstico, como se fosse algo que fugisse a sua responsabilidade e, portanto, se o fazem, é para agradar a mulher ou auxiliá-la. Além disso, outro aspecto comum evidenciado em pesquisas e também encontrado no discurso desses adolescentes, diz respeito aos homens serem os encarregados dos serviços mais pesados relacionados à infraestrutura da casa, enquanto as mulheres seriam encarregadas de cozinhar, limpar, entre outros (Cursino, 2010) como ilustra a seguinte fala:

Os meninos geralmente fazem a parte mais pesada, por exemplo, mudar o sofá de lugar, às vezes eu mudo com a minha mãe mas quando tem meu irmão é mais fácil pra ele fazer. Meu pai? Não porque ele trabalha o dia todo, daí não. (Eduarda, 16)

A nova estruturação social traz com ela muitas novidades e desafios, a dinâmica familiar se transformou, o casal do século XXI trabalha, divide despesas, compartilha responsabilidades financeiras, domésticas e de educação dos filhos e tem como grande desafio conciliar a vida doméstica e a profissional (Goldenberg, 2001). Porém, essa suposta simetria na divisão de serviços é falsa, e a realidade é que a mulher vive o grande desafio de superar as expectativas historicamente enraizadas como seus objetivos de vida: ser boa mãe, boa esposa e dona do lar (Pratta \& Santos, 2007). A percepção dessa falsa simetria incomodou Marina (15) que aponta que as mulheres geralmente trabalham mais nos serviços domésticos, no entanto, ela defende que isso não deveria ser assim.

\section{Identificação de comportamentos sexistas no cotidiano familiar}

Embora os entrevistados tenham demonstrado certo desconhecimento sobre gênero e o tenham interpretado como equivalente à sexualidade, quando perguntados sobre situações em que se sentiram coagidos a agir de determinado modo devido ao seu gênero e sobre a diferenciação que os próprios pais faziam sobre o que era feminino e masculino, situações cotidianas de reprodução ideológicas de discriminação de gênero foram identificadas. Um fator recorrente ecoado por muitas participantes diz respeito à dissonância do que é esperado moralmente no aspecto sexual de meninos e meninas, elas ressaltaram como a liberdade sexual é incentivada para os meninos enquanto é reprimida para meninas, como é possível perceber na fala:

Eu namoro ... aí, minha mãe fala "é, não pode fazer chupão [sic] porque aí vão te chamar de puta [sic]” mas, agora se, por exemplo, eu fizesse um chupão [sic] nele iam me chamar de puta [sic] e se ele fizesse em mim iam me chamar de puta [sic] porque eu deixei, agora nunca vão reprimir o menino, entendeu? É isso que eu acho... que a culpa é sempre da mulher, é sempre ela que é culpada. (Gisele, 15)

Assim, a construção social de pertencimento a determinado sexo se dá através de padrões sociais e culturais e é resultante de tratamentos diferenciados para meninos e 
meninas, incluindo justamente expressões ligadas à sexualidade. Koller e Narvaz (2004) já haviam comentado como as meninas são educadas com o intuito de atenderem as necessidades dos homens e não as suas próprias, além disso, sabe-se que a sexualidade feminina é alvo de repressão, portanto, também nesse aspecto as meninas deveriam responder aos desejos masculinos e - de forma alguma - dar vazão aos seus próprios.

$\mathrm{O}$ argumento biológico bastante difundido de que fisiologicamente o macho tende a querer copular com o número maior de fêmeas para aumentar chances de reprodução enquanto a fêmea é fiel ao parceiro que a proteja é usado como embasamento para mais uma norma social construída culturalmente ser vista como natural (Brym, et al., 2006). No entanto, ao estudar a história da sexualidade, Foucault (1988) elucida claramente como a sexualidade é um dos aspectos mais controlados pela sociedade, que o faz tão eficazmente através de discursos científicos, religiosos e culturais.

No que diz respeito à fala das participantes, expectativas sobre como meninas deveriam ser portar, como deveriam se vestir, que tipo de atividades eram adequadas para elas também foram mencionadas no discurso de todas. Eduarda (16) contou que a postura dela ao sentar com as pernas abertas é um problema para os pais, Manuela (16) passa pela mesma situação. Já Bianca (16) relatou que pelo intenso calor, costuma ficar apenas de sutiã em sua casa, porém, é repreendida pelo seu avô "porque mulher não pode ficar sem camisa em casa”. A questão do vestuário feminino também é apontada por outra perspectiva por Camila (16) que não gosta de usar saia nem vestido, mas diz ser obrigada pelos pais em situações formais a fazê-lo, Gisele (15) reclama da ligação que sua mãe faz entre sua roupa e a impressão que isso causaria sobre ela: "Ela ficou muito com esse pensamento de tipo uma menina sempre que usa roupa curta, ela é uma vagabunda, e ela não quer..."

O papel de gênero é facilmente identificado no discurso dos participantes quando eles relatam como os pais fazem uso do argumento que ele é pertencente a determinado sexo por isso não pode assumir determinada postura, em especial chama a atenção a fala de Simone (14) que anteriormente havia mencionado não haver "diferenciação de coisas de menino e coisas de menina" em sua casa, mas, posteriormente, evidenciou perfeitamente um caso de naturalização de papéis femininos e masculinos:

Ele (o pai) dizia que tocar violão era de menino ... Teve uma vez que meu pai ia colocar meu irmão pra fazer uma atividade, acho que era karatê, aí eu disse que queria ir também, só que aí ele disse que tal coisa, bater, aprender a lutar, sei lá... [sic $]$ a ter força seria só coisa de menino.

Desse modo, é claro como se trata de uma reprodução de papéis de gênero visto que o pai de Simone (14) se mostra preocupado em ensinar a filha qual o padrão de comportamento adequado ao seu gênero no convívio social (Cardoso, 2008). No caso, culturalmente associou-se à mulher propriedades afetivas e sensíveis, enquanto aos homens a racionalidade e a agressividade, porém, essas normas estão tão enraizadas na estrutura social que os pais passam a reproduzi-las como se fosse algo dado à priori. A partir daí, surgem mais regras, ou seja, já que mulheres são essencialmente dóceis e frágeis, logo, não devem praticar esportes envolvendo lutas ou, até mesmo, essencializações sem qualquer fundamento como na distinção de cores masculinas e femininas (Praun, 2011), destacados na fala de Eduarda (16) que contou como sua prima não podia escolher nada de cor azul "porque é de menino". 
Percebe-se como diferentes atividades e objetos são utilizados como mecanismos de elaboração de significados sociais e culturais que irão diferenciar as categorias sexuais e sendo repassados aos indivíduos desde seu nascimento (Praun, 2011). A diferenciação dos papéis de gênero e suas atividades é fomentada na família, nas escolas, pela mídia e outros meios de informação e conhecimento. Mesmo na contemporaneidade, nos parece que as culturas patriarcais se mantêm imortalizadas através de alguns comportamentos e papéis sociais arraigados ao homem e à mulher. Há resistência das pessoas à mudança contínua, acarretando consequências danosas com desfechos de violências (Serpa, 2010).

Ao contrário dos que muitos pensam, a ideologia de gênero também causa efeitos negativos aos meninos, por mais que as desigualdades de gênero sirvam como manutenção do sistema patriarcal, cuja a base é a imposição da dominação masculina, as expectativas de características de masculinidade impostas a eles também são opressoras e violam a construção de suas identidades e subjetividades (Koller \& Narvaz, 2004). De fato, já que as características masculinas são consideradas superiores, um homem que apresenta características femininas é altamente repudiado e julgado na sociedade patriarcal. Foi evidenciado na fala dos adolescentes que situações banais como o fato de um menino querer usar o salto alto da irmã, o batom da mãe, ou acessórios para cabelo como relatado por Marina (15) e Simone (14) ser motivo de repreensão por parte dos pais. Embora Bianca (15) tenha notado que na educação dos seus primos homens há muito mais liberdade e é bem menos controlada que a das suas primas, ela também identifica situações sexistas:

Meu primo se depila e meu avô diz que isso não é atitude de menino, e a mesma coisa quando eu era pequena, eu gostava um pouco de brincar bastante de correr, de futebol e meu avô dizia que isso não era atitude de menina, que era para eu parar.

De maneira geral, todos os adolescentes afirmaram já haver se sentido coagido a agir de determinado modo devido ao seu gênero, apenas uma começou respondendo que não e ao final concluiu: "No fundo a pessoa quer dizer, de verdade, que não deve fazer isso por que você é uma menina” (Hélida, 16). Considerando a socialização como responsável pela internalização de papéis de gênero, os resultados da pesquisa mostram como a desigualdade de gênero na família contemporânea ainda atua como grande força nesse processo. Há, de fato, uma essencialização do que é esperado de meninos e meninas (Praun, 2011), como se nota na fala de Manuela (16):

Boneca é menina, carro é menino... tá entendendo? Não é um preconceito que eles (os pais) tem porque eles não tem, em relação a gêneros, mas, assim, é o normal da sociedade, né [sic], quando carro é de menino, boneca é de menina, então, assim... eles procuram fazer meio que essa diferença, sabe?

A "normalidade" da distinção nada mais é do que a conversão de diferenças em desigualdades que irão atuar como justificativas para a opressão (Koller \& Narvaz, 2004). O conceito de gênero diz respeito às relações sociais baseado no que é informado através da educação doméstica, escolar e social. Desde a infância, nas atividades do cotidiano até as atividades laborais, as pessoas são informadas sobre o que são atividades e comportamentos 
de meninos e de meninas, mantendo a correspondência com o sexo biológico (Lima et al., 2017). Assim, só será possível uma mudança no cenário desigual quando padrões educacionais, repassados de geração a geração, forem questionados por pais e filhos:

Ela (mãe) falou que eu tinha que entender que certas coisas menina não podiam fazer e que menino podia, que era uma questão mais de... sei lá.. De sempre. Que a sexualização [sic] tava presente no dia a dia e que eu tinha que lidar com isso. (Bianca, 15)

\section{Considerações finais}

O estudo teve como objetivo compreender a percepção dos adolescentes sobre a imposição dos papéis de gênero em sua educação familiar. Através do conteúdo das entrevistas, da discussão das histórias de vida e de vivências sociais evidenciadas pelos participantes, foi possível identificar sinais de desconhecimento sobre o tema e de imposição de papéis de gênero no contexto familiar através da prática da socialização e de orientação na educação doméstica.

Outro achado no estudo foi perceber que, embora os participantes concordem com a importância na atualidade de uma educação direcionada para a igualdade de gênero, justificam o comportamento dos pais argumentando a diferença das crenças e valores provenientes da geração. Esse achado revela também o cuidado dos filhos para com seus pais e certa dificuldade vivenciada para descordar e/ou enfrentar essas figuras de autoridade.

Através dos resultados é possível pensar também que, mesmo que essa imposição não seja feita de forma autoritária nem através de violências, elas podem se tornar complicadoras no processo de construção da identidade subjetiva dos indivíduos e afetar o desenvolvimento psicológico, bem como a consciência crítica do lugar ocupado por cada um no mundo. Considerando que a sociedade demanda tempo para modificar crenças e valores e que a violência de gênero é uma realidade que está sendo combatida, sugere-se a implementação de políticas públicas, educação continuada e a socialização e multiplicação de informações pela escola e demais meios de comunicação.

Importante ressaltar que para essa questão a mudança social deve ser considerada como plataforma privilegiada, pois ao alterar os padrões sexistas presentes na educação familiar será possível pensar na promoção e prevenção da saúde mental. A redução do ódio, da repressão, do controle e do preconceito na primeira instituição social da qual o sujeito faz parte resultaria em melhores desfechos.

O estudo possui limitações metodológicas. Sugere-se pesquisas tanto com abordagem quantitativa quanto qualitativa. Implementar estudos com participantes oriundos de escolas diferentes (rede pública e privada) talvez revelasse perspectivas diferentes. Implementar pesquisas com os pais seria de grande ajuda para que fosse possível compreender as questões de gênero nessa população. 


\section{Referências}

Abranches, C. D. \& Assis, S. G. (2011). A (in)visibilidade da violência psicológica na infância e adolescência no contexto familiar. Cad. Saúde Pública, Rio de Janeiro, 27(5), 843-854.

Bardín, L. (1979). Análise de Conteúdo. Lisboa: Edições 70.

Bidarra, Z. \& Gregoria, F. (2008). Configurações da violência psicológica contra crianças e adolescentes no município de Toledo (PR). Recuperado de file:///C:/Users/ASUS/ Downloads/1810-6491-1-PB.pdf

Brym, R., Lie, J., Hamlin, C., Mutzenberg, R., Soares, E., \& Maior, H. S. (2006). Sociologia: sua bússola para um novo mundo. São Paulo: Thomson Learning.

Cardoso, F. (2008). O Conceito de Orientação Sexual na Encruzilhada entre Sexo, Gênero e Motricidade. Revista Interamericana de Psicología/Interamerican Journal of Psychology, 42(1), 69-79.

Carvalho, M. \& Machado, J. (2006). Análise dos usos do tempo entre crianças acerca das relações de gênero e de classe social. Currículo sem Fronteiras, 6(1),70-81.

Cortez, M. \& De Souza, L. (2013). Mulheres de classe média, relações de género e violência econjugal: um estudo exploratório. Rev. Gerenc. Polit. Salud, 12(24), 34-53.

Cursino, R. (2010). Relações de gênero em famílias heterossexuais de classe média da cidade do Recife: sobre discursos e posicionamentos. Dissertação de Mestrado, Programa de Pós-graduação em Psicilogia, Universidade Federal de Pernambuco, Recife.

Elias, M. \& Gauer, G. (2014). Violência de gênero e o impacto na família: Educando para uma mudança na cultura patriarcal. Sistema Penal ङ゚ Violência, Porto Alegre, 6(1), 117-128.

De Sousa, Alípio. (2011). Orientação sexual: construção política do desejo, ou crítica da substancialização. In I. M. Gentile, M. N. Tavares Zenaide, \& V. M. G. Guimarães (Orgs.), Gênero, Diversidade Sexual e Educação: conceituação e práticas de direito e políticas públicas (pp. 55-66). João Pessoa: Editora da Universidade Federal da Paraíba.

Fonseca, A. \& Gomes, V. (2004). Manifestações de gênero no processo de adolescer. Acta Scientiarum. Health Sciences, Maringá, 26(1), 231-237.

Foucault, M. (1988). História da sexualidade I: a vontade de saber. Rio de Janeiro: Graal.

Goldani, A. (1993). As famílias no Brasil contemporâneo e o mito da desestruturação. Cadernos Pagu, Unicamp, 1, 67-1 10.

Goldenberg, M. (2001). Sobre a invenção do casal. Estudos e Pesquisas em Psicologia, Rio de Janeiro, 1(1), 89-104.

Gomes, N., Diniz, N. M. F., Araújo, A. J. S., \& Coelho, T. M. F. (2007). Compreendendo a violência doméstica a partir das categorias gênero e geração. Acta Paulista de Enfermagem, 20(4), 504-508.

Jablonsksi, B. (2010). A divisão de tarefas domésticas entre homens e mulheres no cotidiano do casamento*. Psicol. Cienc. Prof., Brasília, 30(2), 262-275.

Koller S. H. \& Narvaz, M. G. (2004). Famílias, gêneros e violência: desvelando as tramas da transmissão transgeracional da violência de gênero. In M. N. Strey, M. P. R. Azambuja, \& F. P. Jaeger (Eds.), Violência, gênero e políticas públicas (pp. 149-176). Porto Alegre: Editora da Pontifícia Universidade Católica do Rio Grande do Sul. 
Lima, F., Voig, A. E. G., Feijó, M. R., Camargo, M. L., \& Cardoso, H. F. (2017). A influência da construção de papeis sociais de gênero na escolha profissional. Rev. Bras. Psicol. Educ., Araraquara, 19(1), 33-50. ISSN: 1413-2060 DOI: 10.30715/rbpe.v19.n1.2017.10818

Mayorga, C. (2006). Identidades e adolescências: uma desconstrução. Pesquisas e Práticas Psicossociais, São João del-Rei, 1(1), 1-20.

Mead, G. H. (1982). Espiritu, persona y sociedad. Buenos Aires: Paidós.

Money, J. (1998). Sin, science, and the sex police: Essays on sexology \& sexosophy. New York: Prometheus Books.

Nascimento, C. R. R. N. \& Trindade, Z. A. (2010). Criando meninos e meninas: investigação com famílias de um bairro de classe popular. Arquivos Brasileiros de Psicologia, 62(2), 187-200.

Neves, S. \& Nogueira, C. (2003). A psicologia feminista e a violência contra as mulheres na intimidade: a (re)construção dos espaços terapêuticos. Psicologia E̋ Sociedade, Porto Alegre, 15(2), 43-64.

Pratta, E. M. M. \& Santos, M. A. (2007). Família e adolescência: a influência do contexto familiar no desenvolvimento psicológico de seus membros. Psicologia em Estudos, (Maringá), 12(2), 247-256.

Praun, A. G. (2011). Sexualidade, gênero e suas relações de poder. Revista Húmus, 1(1), 55-65.

Russo, G., Trindade, H., Dantas, J., \& Nogueira, J. (2014). Quando a realidade cala: Violência psicológica intrafamiliar contra crianças e adolescentes em Mossoró-RN. Temporalis, Brasília, 14(27), 159-180.

Santana, M. \& Dimenstein, M. (2005). Trabalho doméstico de adolescentes e reprodução das desiguais relações de gênero. Psico (USF), 10(1), 93-102.

Santos, J. A. F. (2008). Classe social e desigualdade de gênero no Brasil. Dados (Rio de Janeiro), 51(2), 353-402.

Scott, J. (1990). Gênero: uma categoria útil de análise histórica. Educação E̊ Realidade. $16(2), 5-22$.

Serpa, M. G. (2010). Perspectivas sobre papéis de gênero masculino e feminino: um relato de experiência com mães de meninas vitimizadas. Psicologia E̊ Sociedade, 22(1), 14-22.

Silva, L., Coelho, E., \& Caponi, S. (2007). Violência silenciosa: violência psicológica como condição da violência física doméstica. Interface - Comunicação, Saúde, Educação, 11(21), 93-103.

Stoller, R. (1993). Presentations of gender. London: Yale University Press.

Weber, M. (1971). Ensaios de Sociologia (2 ${ }^{\mathrm{a}}$ ed.). Rio de Janeiro: Zahar. 


\section{JULIA BAERLOCHER CARVALHO \\ https://orcid.org/0000-0002-8772-0742}

Graduada em Ciências Sociais pela Universidade Federal de Pernambuco (2015) e cursando Psicologia pela Faculdade Pernambucana de Saúde.

Endereço: FPS - Psicologia. Av. Mal. Mascarenhas de Morais, 4861 Imbiribeira, Recife/PE, CEP $51150-000$

E-mail: juliabaerlocher@,hotmail.com

\section{MÔNICA CRISTINA MELO}

https://orcid.org/0000-0002-8504-5501

Psicóloga pela Universidade Católica de Pernambuco, Especialista em Psicologia Hospitalar, mestre e doutora em Saúde Materno Infantil pelo Instituto de Medicina Integral Prof. Fernando Figueira - IMIP. Pósdoutorado em Ciências da Saúde pela Universidade Federal do Rio Grande do Norte (UFRN). Atua como Psicóloga no Instituto de Medicina Integral Prof. Fernando Figueira- IMIP no Setor de Psicologia - Laboratório de Avaliação Psicológica - LAP e em consultório. Docente permanente no Mestrado Profissional em educação para o Ensino na Área de Saúde e Mestrado profissional em Psicologia da Saúde da Faculdade Pernambucana de Saúde - FPS.

E-mail: monicacbmelo@gmail.com

\begin{tabular}{|c|c|}
\hline Histórico & $\begin{array}{l}\text { Submissão: 31/08/2016 } \\
\text { Revisão: 24/07/2019 } \\
\text { Aceite: 25/10/2019 }\end{array}$ \\
\hline Contribuição & $\begin{array}{l}\text { Concepção: J.B.; M.M. } \\
\text { Coleta de dados: J.B. } \\
\text { Análise de dadlos: J.B. } \\
\text { Elaboração do manus crito: J.B.; M.M. } \\
\text { Final aprovação do manuscrito: J.B.; M.M. }\end{array}$ \\
\hline Financiamento & Não se aplica. \\
\hline $\begin{array}{l}\text { Consentimento de } \\
\text { uso de imagem }\end{array}$ & Não se aplica. \\
\hline $\begin{array}{l}\text { Aprovação ética e } \\
\text { consentimento }\end{array}$ & $\begin{array}{l}\text { Comitê de Ética em Pesquisa do Instituto de Medicina } \\
\text { Integral Professor Fernando Figueira, parecer número } \\
1.334,669\end{array}$ \\
\hline
\end{tabular}

